\title{
A Decomposition of the Atlantic Meridional Overturning
}

\author{
LOUISE C. SimE* \\ School of Environmental Sciences, University of East Anglia, Norwich, United Kingdom \\ DAVID P. STEVENS \\ School of Mathematics, University of East Anglia, Norwich, United Kingdom \\ Karen J. Heywood and Kevin I. C. Oliver \\ School of Environmental Sciences, University of East Anglia, Norwich, United Kingdom
}

(Manuscript received 5 July 2005, in final form 5 May 2006)

\begin{abstract}
A decomposition of meridional overturning circulation (MOC) cells into geostrophic vertical shears, Ekman, and bottom pressure-dependent (or external mode) circulation components is presented. The decomposition requires the following information: 1) a density profile wherever bathymetry changes to construct the vertical shears component, 2) the zonal-mean zonal wind stress for the Ekman component, and 3 ) the mean depth-independent velocity information over each isobath to construct the external mode. The decomposition is applied to the third-generation Hadley Centre Coupled Ocean-Atmosphere General Circulation Model (HadCM3) to determine the meridional variability of these individual components within the Atlantic Ocean. The external mode component is shown to be extremely important where western boundary currents impinge on topography, and also in the area of the overflows. The Sverdrup balance explains the shape of the external mode MOC component to first order, but the time variability of the external mode exhibits only a very weak dependence on the wind stress curl. Thus, the Sverdrup balance cannot be used to determine the external mode changes when examining temporal change in the MOC. The vertical shears component allows the time-mean and the time-variable upper North Atlantic MOC cell to be deduced at $25^{\circ} \mathrm{S}$ and $50^{\circ} \mathrm{N}$. A stronger dependency on the external mode and Ekman components between $8^{\circ}$ and $35^{\circ} \mathrm{N}$ and in the regions of the overflows means that hydrographic sections need to be supplemented by bottom pressure and wind stress information at these latitudes. At the decadal time scale, variability in Ekman transport is less important than that in geostrophic shears. In the Southern Hemisphere the vertical shears component is dominant at all time scales, suggesting that hydrographic sections alone may be suitable for deducing change in the MOC at these latitudes.
\end{abstract}

\section{Introduction and aims}

The meridional overturning circulation (MOC) in the Atlantic Ocean strongly influences the climate of northwestern Europe, and is a key part of the planetary climate system (e.g., Vellinga and Wood 2002). The upper

* Current affiliation: Physical Sciences Division, British Antarctic Survey, Cambridge, United Kingdom.

Corresponding author address: Louise C. Sime, Physical Sciences Division, British Antarctic Survey, Cambridge CB3 0ET, United Kingdom.

E-mail: 1sim@bas.ac.uk
North Atlantic and lower Antarctic MOC cells both play a significant role in the distribution of heat within the Atlantic Ocean system. Each cell is made up of a combination of buoyancy-driven baroclinic and barotropic geostrophic flows, wind-driven Ekman transports, and other ageostrophic components. Understanding the contribution of each MOC component and their interactions is critical for determining how the MOC may respond to changes in atmospheric forcing over a range of time scales.

Zonal hydrographic sections offer a direct means of calculating MOC and heat transport in the Atlantic (e.g., Bryan 1962). The basin has zero net meridional volume transport, apart from a small Bering Strait 
throughflow and surface freshwater fluxes. This makes such calculations easier in the Atlantic as compared with other ocean basins, where throughflows complicate the situation. However, one-off or repeat hydrographic zonal sections are likely to be influenced by seasonal and lower-frequency fluctuations in the MOC components. This study aims to clarify this question of hydrographic section representativeness in the calculation of the MOC at all latitudes in the Atlantic. This is achieved by deriving and applying a decomposition of MOC components to a coupled global circulation model (GCM).

Hall and Bryden (1982) decomposed heat transport across a hydrographic section into contributions from the barotropic, Ekman, and baroclinic components. This method has subsequently been used by a number of authors (e.g., Saunders and King 1995; Böning et al. 2001). In this paper we further develop a decomposition originally employed by Lee and Marotzke (1998) and Baehr et al. (2004). This decomposition allows us to separate out geostrophic vertical shears, Ekman, and bottom pressure-dependent (or external mode) circulation components. Of these components, the variability of the external mode component of the MOC is not well known and is sometimes neglected. Consequently, the impact of the external mode on reference-level information used in observational studies of the MOC is also not well understood (e.g., Koltermann et al. 1999). This decomposition represents a chance to determine the latitudinal variability in sensitivity to referencelevel velocity information. We present the decomposition in a generalized form, and in this study apply it to the zonal integral of the circulation components in a GCM.

GCMs are the best available tool to investigate how the components of Atlantic MOC interact on seasonal and longer time scales. We use the control integration of the third-generation Hadley Centre Coupled OceanAtmosphere GCM (HadCM3), a global non-fluxadjusted coupled atmosphere-ocean GCM. HadCM3 has been shown to represent a stable realistic oceanic and atmospheric climatology (Gordon et al. 2000). Additionally, Böning et al. (2001) noted that this class of Cox- (1984) type models does not differ substantially from other classes of models in their seasonal anomalies. Willebrand et al. (2001), however, showed that the annual-mean patterns of MOC transport and the structure of the western boundary currents do differ. Using $100 \mathrm{yr}$ of the HadCM3 control run allows us to examine seasonal-to-decadal variability in MOC components, without contending with any significant model drift in properties or behavior.

Previous authors have focused on the impact of
MOC variability on the optimum design for a monitoring array at $26^{\circ} \mathrm{N}$, with the purpose of detecting any trend in MOC transport (Hirschi et al. 2003; Baehr et al. 2004). Here, we are interested in the components underlying variability in the MOC at seasonal-todecadal time scales. We present a generalized decomposition of the MOC and apply this to latitudes between $30^{\circ} \mathrm{S}$ and $70^{\circ} \mathrm{N}$. Additionally, three frequency bands, each characterized by time variability of a different nature, are considered in turn, generating a complete picture of the variability of these components within both hemispheres. This provides a quantitative, if model-based, estimate of the errors associated with the time-mean assumption in analysis of hydrographic, wind, and barotropic flow fields, and has the potential to assist in identifying improvements on this approach.

\section{Model description: HadCM3}

The ocean component of HadCM3 is a 20-level Cox(1984) type ocean model on a $1.25^{\circ}$ latitude $\times 1.25^{\circ}$ longitude Arakawa B grid (Gordon et al. 2000), and is based on the primitive equations. The vertical levels are distributed to have enhanced resolution near the ocean surface. Each high-latitude ocean grid box can have partial sea ice cover. The atmospheric component of HadCM3 also has a regular latitude-longitude grid with a lower horizontal resolution of $2.5^{\circ} \times 3.75^{\circ}$, and 19 hybrid coordinate levels in the vertical (Pope et al. 2000). The Bering Strait is closed in the model (Pardaens et al. 2003) ensuring no net Atlantic meridional transport (except for insignificant surface fluxes).

Roberts and Wood (1997) showed that Bryan-Coxtype models can be sensitive to the depth of the various channels along the Greenland-Iceland-Scotland Ridge. Many of these channels are subgrid scale and so three routes (one grid point wide on the velocity grid) through the ridge represent the total of the subgridscale channels in HadCM3. These lead to a long-term mean outflow of approximately $8.5 \mathrm{~Sv}\left(1 \mathrm{~Sv} \equiv 10^{6}\right.$ $\mathrm{m}^{3} \mathrm{~s}^{-1}$ ) of deep water from the Greenland-IcelandNorwegian Sea in the coupled simulation. This compares to the observed outflow of around 5-6 Sv by Dickson and Brown (1994), or 4-8 Sv by Bacon (1998). Convective adjustment in the region of the Denmark Strait and Iceland-Scotland Ridge is modeled so as to represent the downslope mixing of the overflow water, allowing it to find its level of neutral buoyancy instead of convectively mixing it through the water column. Thorpe et al. (2004) find that although the density structure in the Labrador Sea does depend upon the specifics of how the mixing of these overflows are modeled, the (global) thermohaline circulation and climate 
responses are not sensitive to these details. While this model setup is still not fully realistic, it has enabled HadCM3 to capture the observed separation of deepwater sources (Gordon et al. 2000; Thorpe et al. 2001).

The models are coupled once per day. The atmospheric model is run with fixed sea surface temperatures through the day and the various forcing fluxes are accumulated each atmospheric model time step. At the end of the day these fluxes are passed to the ocean model, which is then integrated forward in time (Gordon et al. 2000). The fields used in this study are all monthly averages, so the highest temporal resolution model behavior is not examined.

The model climatology is similar to that observed, with an excellent match between model and observation estimates of poleward oceanic heat transport (Cooper and Gordon 2002). Additionally, the run used in this study exhibits realistic low-frequency variability from El Niño-Southern Oscillation and North Atlantic Oscillation events (Collins et al. 2001). However, some salinity and temperature drifts occur throughout the 1400-yr control run (Gordon et al. 2000), with some depth dependence in the drift of these properties (Pardaens et al. 2003). For this reason we restrict analysis to $100 \mathrm{yr}$ of the run to avoid the need to detrend results. In the North Atlantic, slight cooling and freshening still occurs over the period of the run we use, but this is insignificant when compared with 100 -yr interannual model variability. Other noted model deficiencies are in the simulated sea surface temperature front over the Gulf Stream region, which is weaker than observed, and the zonal and meridonal wind stresses are weaker than observed in midlatitudes (Dong and Sutton $2002 b)$. The associated underestimation of the wind stress magnitude is also seen in the atmosphere-only HadAM3 model. See Pope et al. (2000) and Gordon et al. (2000) for more details about internal dynamics and basic climatology.

\section{Method: A decomposition for cross-sectional velocities and fluxes}

It is useful to decompose the velocity across any section into geostrophic and Ekman components (Bryan 1962), because it is reasonable to assume that tidal (averaged over a tidal cycle), frictional, and other ageostrophic contributions are small. The geostrophic component can then be partitioned into barotropic and baroclinic components (Hall and Bryden 1982). The barotropic component represents the vertically averaged velocity, and is therefore a function of horizontal, but not vertical, location, although Wunsch (1996) argued that barotropic flow should strictly be defined as uniform in all spatial dimensions. The baroclinic com- ponent represents deviations from the vertical mean. If the water column is in hydrostatic equilibrium, such deviations can only be caused by horizontal density gradients.

Here, the cross-sectional velocity $\boldsymbol{v}$ is decomposed as follows:

$$
\begin{aligned}
\boldsymbol{v}(x, y, z, t)= & \overline{\boldsymbol{v}}(y, t)+\boldsymbol{v}_{\rho}(x, y, z, t)+\boldsymbol{v}_{\tau}(x, y, z, t) \\
& +\boldsymbol{v}_{*}(x, y, t)+\boldsymbol{v}_{E}(x, y, z, t),
\end{aligned}
$$

where $x, y$, and $z$ are the along-sectional, crosssectional, and vertical (positive upward) coordinates, respectively, and $t$ is time; $\boldsymbol{v}$ is the section-mean velocity, $\boldsymbol{v}_{\rho}$ is the geostrophic vertical shears component, $\boldsymbol{v}_{\tau}$ is the Ekman component, $\boldsymbol{v}_{*}$ is the depth-independent external mode component, and $\boldsymbol{v}_{E}$ contains small ageostrophic terms and errors resulting from imperfect sampling. Our terminology follows that of Lee and Marotzke (1998).

The various components are most useful if their section integrals are each equal to zero, because this facilitates calculations of their contribution to overturning and gyre transports, as well as heat and freshwater fluxes. For this reason, we define our components slightly differently in comparison with those of Hall and Bryden (1982). The section-integrated Ekman component is unlikely to be zero, but, if the section encloses a part of the ocean, volume conservation requires a balancing return flow. Following Baehr et al. (2004), we subtract a barotropic velocity of equal magnitude from this term to obtain the Ekman component $\boldsymbol{v}_{\tau}$; the implications of this are discussed below. If the vertical shears term is taken to be the zero vertical-mean geostrophic velocity, then its column integral (and therefore its section integral) is zero. Defined in this way, $\boldsymbol{v}_{\rho}$ can be inferred from the temperature and salinity field, without any additional information. The depthindependent flow is separated into a section mean $\overline{\boldsymbol{v}}$, and the residual once the mean is removed is $\boldsymbol{v}_{*}$. Section-mean velocity $\overline{\boldsymbol{v}}$ is the only component that may integrate over the section to a nonzero volume transport, although in the HadCM3 Atlantic Ocean, the closure of the Bering Strait leads to $\overline{\boldsymbol{v}}=0$, simplifying our decomposition. Using this decomposition we are able to quantify the role in overturning of nonuniform depth-independent external mode, which can be an elusive quantity.

Nonzero $\boldsymbol{v}_{E}$ may arise because of imperfect sampling or the presence of ageostrophic terms (other than the Ekman component). In this study, however, the use of depth-independent velocity, rather than pressure, fields means that depth-independent ageostrophic flow is not included in $\boldsymbol{v}_{E}$. If $\boldsymbol{v}$ is obtained using the same data and 
assumptions that are used in obtaining each component, as is typically the case in hydrographic section inversions, $\boldsymbol{v}_{E}=0$ would be obtained. In this study, $v$ is instead obtained directly from HadCM3 (which does not assume geostrophic balance), and the output density and velocity fields have each been monthly averaged. Thus, we anticipate that $\boldsymbol{v}_{E} \neq 0$, but is still small.

Herein, $x$ is taken to be eastward and $y$ is taken to be northward. The northward velocity is given by

$$
\begin{aligned}
\boldsymbol{v}= & \frac{1}{\rho_{0} f}\left\{\left[\frac{\partial p(x, y, z, t)}{\partial x}\right]-\frac{H\left[z+h_{\tau}(x, y)\right] \tau_{x}(x, y)}{h_{\tau}(x, y)}\right\} \\
& +\boldsymbol{v}_{a}(x, y, t)+\boldsymbol{v}_{E}(x, y, z, t),
\end{aligned}
$$

where $p$ is pressure, $\tau_{x}$ is the zonal wind stress, $\rho_{0}$ is a reference density, $f$ is the Coriolis parameter, $h_{\tau}$ is the Ekman-layer depth, and $\boldsymbol{v}_{a}$ contains any depth-independent ageostrophic flow; $H$ is the Heaviside function and so $H\left(z+h_{\tau}\right)$ gives 1 in the Ekman layer (top 10-m layer of the model) and 0 elsewhere. The geostrophic term can be decomposed as

$$
\begin{aligned}
\frac{\partial p}{\partial x}= & \frac{\partial p_{m}(x, y, t)}{\partial x}-g\left[\int_{-h_{b}(x, y)}^{z} \frac{\partial \rho(x, y, Z, t)}{\partial x} d Z\right] \\
& +\left(\frac{\partial p_{\rho}}{\partial x}\right)(x, y, t),
\end{aligned}
$$

where $h_{b}$ is the local bathymetric depth, $g$ is the acceleration resulting from gravity, $\partial p_{m} / \partial x$ is the verticalmean horizontal pressure gradient in the water column, and

$$
\left(\frac{\partial p_{\rho}}{\partial x}\right)=-\frac{g}{h_{b}}\left[\int_{-h_{b}}^{0} \int_{-h_{b}}^{z} \frac{\partial \rho(x, y, Z, t)}{\partial x} d Z d z\right] .
$$

If the vertical shears circulation is defined as circulation that is directly driven by temperature and salinity gradients, then the last two terms in (3) form this thermohaline component-the only terms containing $\rho$. Thus, for the vertical shears velocity $\left(\boldsymbol{v}_{\rho}\right)$, we can write

$$
\boldsymbol{v}_{\rho}=-\frac{1}{\rho_{0} f}\left\{\left[g \int_{-h_{b}}^{z} \frac{\partial \rho(x, y, Z, t)}{\partial x} d Z\right]-\frac{\partial p_{\rho}}{\partial x}\right\} .
$$

Integrating the Ekman transport over the section and dividing by area provides us with a uniform (in both the vertical and along-sectional dimensions) velocity to be removed from the Ekman velocity to yield the Ekman component

$$
\boldsymbol{v}_{\tau}=-\frac{1}{\rho_{0} f}\left[\frac{H\left(z+h_{\tau}\right) \tau_{x}}{h_{\tau}}-\frac{\partial p_{\tau}}{\partial x}\right], \quad \frac{\partial p_{\tau}}{\partial x}=\frac{L_{0} \overline{\tau_{x}}}{A},
$$

where $\overline{\tau_{x}}$ is the zonal-mean zonal wind stress and $L_{0}$ is the basin width at the surface. The component is writ- ten in terms of a pressure gradient to emphasize that this response is geostrophic. We anticipate that the Ekman-compensating return flow is poorly represented as being uniform in the along-sectional dimension. Deviations from this are contained in $\boldsymbol{v}_{*}$; thus, we would expect correlation between $\boldsymbol{v}_{\tau}$ and $\boldsymbol{v}_{*}$. Nevertheless, any improvement on this approach would need to be made a posteriori.

Substituting (1) into (2) and subtracting $\boldsymbol{v}_{\rho}, \boldsymbol{v}_{\tau}$, and $\left[H\left(z+h_{\tau}\right) \tau_{x} / h_{\tau}\right]-\left(\partial p_{\tau} / \partial x\right) \overline{\boldsymbol{v}}$ leaves us with

$$
\boldsymbol{v}_{*}=\frac{1}{\rho_{0} f}\left(\frac{\partial p_{m}}{\partial x}-\frac{\partial p_{\tau}}{\partial x}\right)+\boldsymbol{v}_{a}-\overline{\boldsymbol{v}} .
$$

Because HadCM3 outputs velocities rather than pressure gradients, the vertical-mean velocity $\boldsymbol{v}_{m}$ is a more useful variable than the vertical-mean horizontal pressure gradient, so we write

$$
\boldsymbol{v}_{m}=\frac{1}{\rho_{0} f}\left(\frac{\partial p_{m}}{\partial x}-\frac{\tau_{x}}{h_{b}}\right)+\boldsymbol{v}_{a} .
$$

Substituting into (7),

$$
\boldsymbol{v}_{*}=\left(\boldsymbol{v}_{m}-\overline{\boldsymbol{v}}\right)+\frac{1}{\rho_{0} f}\left(\frac{\tau_{x}}{h_{b}}-\frac{L_{0} \overline{\tau_{x}}}{A}\right) .
$$

The first part contains the anomaly in vertically averaged velocity, relative to the section mean. Subtracting the second part removes the anomaly in vertically averaged Ekman velocity, caused by horizontal variations in zonal wind stress or bathymetric depth. This leaves the anomaly in depth-independent flow, the section integral of which is zero. We note that while $\boldsymbol{v}_{\tau}$ and $\boldsymbol{v}_{\rho}$ are defined as the Ekman and vertical shears components, wind- and density gradient-driven circulation plays a strong role in determining $\boldsymbol{v}_{*}$, but their contributions cannot be extracted from instantaneous velocity, density, and wind stress fields.

The HadCM3 output overturning streamfunction is

$$
\psi(y, z, t)=-\int_{-h}^{z} \int_{x_{w}(y, Z)}^{x_{e}(y, Z)} \boldsymbol{v}(x, y, Z, t) d x d Z,
$$

where $x_{e}(y, Z)$ and $x_{w}(y, Z)$ are the locations of eastern and western boundaries, respectively, at depth $Z$, and $h$ is the maximum bathymetric depth of the section. The maximum in $\psi$ represents the Atlantic cell and is defined as $\psi_{N}$; the location at which this occurs is $z_{N}$. The minimum (maximum negative) value below $z_{N}$ represents the Antarctic cell and is defined as $\psi_{S}$, with location $z_{S}$. Figure 1a shows the 100 -yr mean $\psi$.

Similarly, we integrate $\boldsymbol{v}_{\rho}, \boldsymbol{v}_{\tau}$, and $\boldsymbol{v}_{*}$ along the section and vertically to obtain the overturning streamfunctions of the three components, 

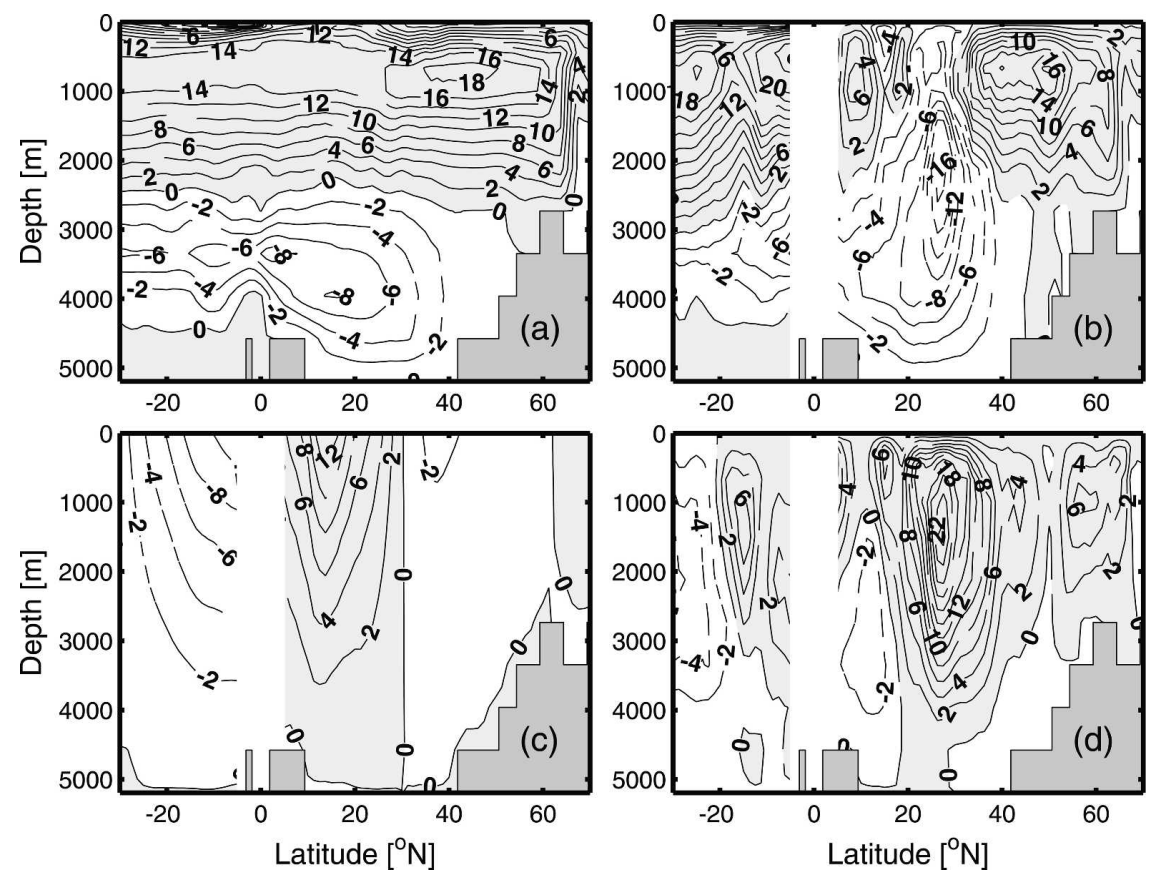

FIG. 1. The 100-yr mean MOC diagnostics for the Atlantic Ocean in the HadCM3 control run: (a) $\psi$, the total overturning, (b) $\psi_{\rho}$, the thermohaline or vertical shears component, (c) $\psi_{\tau}$, the Ekman component, and (d) $\psi_{*}$, the external mode component. Gray shading and positive values indicate clockwise (looking west) overturning; white indicates anticlockwise overturning. Contour intervals are $2 \mathrm{~Sv}$. The overturning is not decomposed within $5^{\circ}$ of the equator.

$$
\begin{aligned}
\psi_{\rho}(y, z, t)= & \frac{1}{\rho_{0} f}\left\{\int_{-h}^{z}\left[g \int_{-h}^{Z} \hat{\rho}\left(y, Z^{\prime}, t\right) d Z^{\prime}\right]\right. \\
& \left.-\hat{p}_{\rho}(y, Z, t) d Z\right\}
\end{aligned}
$$

where

$$
\hat{p}_{\rho}(y, z, t)=\int_{x_{w}(y, z)}^{x_{e}(y, z)} \frac{\partial p_{\rho}}{\partial x} d x, \quad \hat{\rho}=\rho\left(x_{e}, z\right)-\rho\left(x_{w}, z\right),
$$

and $h$ is the maximum bathymetric depth of the section,

$$
\psi_{\tau}(y, z, t)=\frac{1}{\rho_{0} f} \int_{-h}^{z} \frac{L_{0} H\left(Z+h_{\tau}\right) \overline{\tau_{x}}}{h_{\tau}}-\frac{L(y, Z) L_{0} \overline{\tau_{x}}}{A} d Z
$$

$$
\begin{aligned}
\psi_{*}(y, z, t)= & -\int_{-h}^{z} L(y, Z) \\
& \times\left\{\left(\tilde{\boldsymbol{v}}_{m}-\overline{\boldsymbol{v}}_{m}\right)+\frac{1}{\rho_{0} f}\left[\left(\frac{\overline{\tau_{x}}}{h_{b}}\right)-\frac{L_{0} \overline{\tau_{x}}}{A}\right]\right\} d Z,
\end{aligned}
$$

where $L(y, z)=x_{e}(y, z)-x_{w}(y, z)$, and a tilde indicates the along-sectional average of a property over the region where $h_{b}(x) \geq-z$. These components are depicted in Figs. 1b-1d.

The above definitions of $L, \hat{p}_{\rho}$, and $\hat{\rho}$ are based on the assumption that the section crosses a single basin, with depth monotonically increasing from 0 to $h$ and then monotonically decreasing to 0 . In practice, sections tend to be divided into subbasins by topographic features, particularly in the deep ocean. The analysis is equally applicable in such cases. The terms $\hat{p}_{\rho}$ and $\hat{\rho}$ are the sum of the zonal pressure and density differences, respectively, in each subbasin, and $L$ is the sum of subbasin widths.

The information required to construct each component is as follows. A density profile is required wherever bathymetry changes to reconstruct $\psi_{\rho}$. The zonalmean zonal wind stress is required for $\psi_{\tau}$. The mean velocity [from bottom pressure, or from suitably averaged lowered acoustic Doppler current profiler (LADCP) data] as well as the Ekman contribution to this, over each isobath is needed to reconstruct $\psi_{*}$. A nonzero value of $\psi_{*}$ occurs if there is a correlation between depth-independent flow and bathymetric depth. For example, northward depth-independent flow over shallow isobaths and southward depth-independent flow over deep isobaths would yield positive $\psi_{*}$ between these levels. (If isopycnal coordinates were used, 

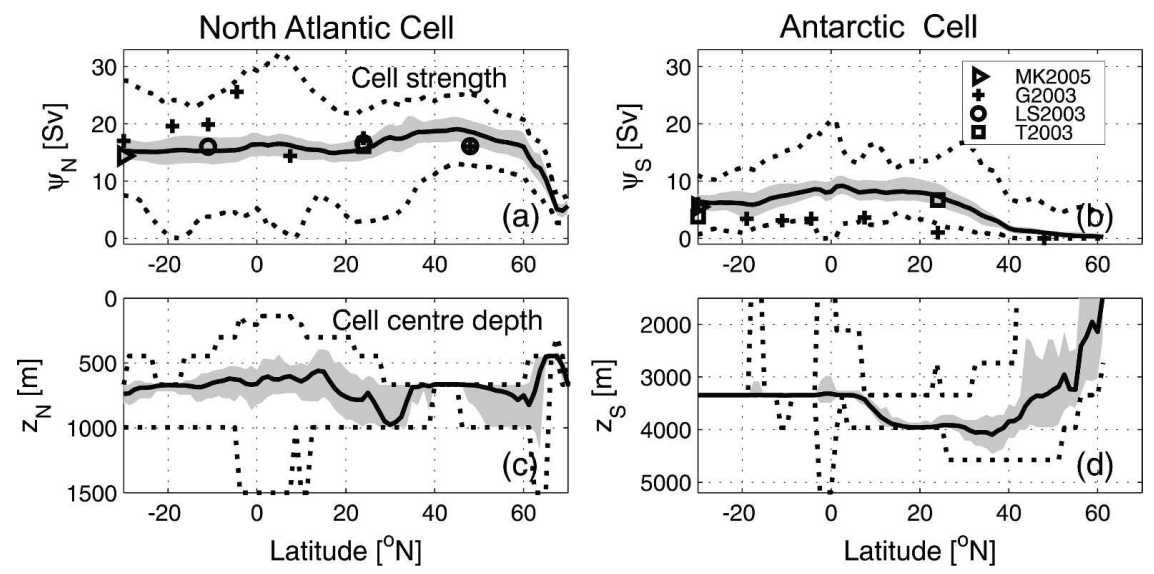

FIG. 2. Components of the (a) North Atlantic $\psi_{N}$ and (b) Antarctic MOC $\psi_{S}$ with inter- and intra-annual variability. The shading shows the range of interannual variability at each latitude. The dotted lines show the range of seasonal variation. The depth of the maximum (c) North Atlantic overturning $z_{N}$, and (d) Antarctic overturning $z_{S}$ with inter- and intra-annual variability. Here (a) and (b) show observations of MK2005: McDonagh and King (2005), G2003: Ganachaud (2003b), LS2003: Lumpkin and Speer (2003), and T2003: Talley (2003).

$\psi_{*}$ would also depend on the correlation between depth-independent flow and isopycnal layer thickness.)

We can now define $\psi_{\rho N}=\psi_{\rho}\left(z_{N}\right), \psi_{\tau N}=\psi_{\tau}\left(z_{N}\right)$, $\psi_{* N}=\psi_{*}\left(z_{N}\right), \psi_{\rho S}=-\psi_{\rho}\left(z_{S}\right), \psi_{\tau S}=-\psi_{\tau}\left(z_{S}\right)$, and $\psi_{* S}=-\psi_{*}\left(z_{S}\right)$, where $z_{N}$ and $z_{S}$ are the depth of the maximum in North Atlantic and Antarctic overturning, respectively. We also define terms representing the effect of nonzero $\boldsymbol{v}_{E}, \psi_{E N}=\psi_{N}-\left(\psi_{\rho N}+\psi_{\tau N}+\psi_{* N}\right)$, and $-\psi_{E S}=\psi_{S}-\left(\psi_{\rho S}+\psi_{\tau S}+\psi_{* S}\right)$. It worth noting that the maximum and minimum of each overturning component is liable to occur at $z \neq z_{N}$ and $z \neq z_{S}$. Changes in the location of the maximum overturning streamfunction will affect the magnitudes of the various components as defined here. For example, if $z_{S}$ increases in depth, the magnitude of $\psi_{\tau S}$ will decrease, independent of any change in $\tau_{x}$, because $\psi_{\tau}$ decreases monotonically from $10-\mathrm{m}$ depth to the bottom. These definitions are useful in allowing a discussion of the MOC and its components in relation to published observational estimates.

\section{The structure of the MOC cells}

HadCM3 depicts an Atlantic MOC with two distinct cells, consistent with our current understanding of the Atlantic circulation. The upper Atlantic cell is fed with North Atlantic Deep Water (NADW) that originates from dense water masses formed in the Nordic seas and the Labrador Sea. The Nordic seas overflows entrain overlying water while flowing southward to attain a maximum strength of $18-22 \mathrm{~Sv}$ between $25^{\circ}$ and $45^{\circ} \mathrm{N}$ (Fig. 2a). The warmer waters of the North Atlantic Current flow north replacing these deep southward cur- rents. The Antarctic cell occupies the lower portion of the basin. It is fed by waters transformed in the Southern Ocean. The northern limit of the cell varies zonally and temporally, but on average is at $60^{\circ} \mathrm{N}$ (Fig. 2b). The horizontal boundary between the two cells is not constant with latitude, but on average is about $3000 \mathrm{~m}$ in depth (Fig. 1a and Fig. 2c). By defining $z_{N}$ and $z_{S}$ as the temporally variable vertical location of the maximum in the Atlantic (Fig. 2c) and Antarctic (Fig. 2d) cells, respectively, we both aid investigation of the meridional and temporal MOC strength and structure of the cells, and enable comparison with observational MOC estimates.

Observational Atlantic MOC estimates are derived from zonal hydrographic sections. Recent studies include those from inverse-box-model studies (McDonagh and King 2005; Ganachaud 2003b; Lumpkin and Speer 2003) and a manual adjustment of geostrophic (plus Ekman) velocities for mass conservation (Talley 2003). Estimates of North Atlantic MOC from these studies are shown on Fig. 2a. For figure clarity, the uncertainties associated with the estimates are not shown. When these uncertainties [of around 3-4 Sv for Ganachaud (2003b)] are taken into consideration, the estimates generally match the model overturning. Estimates from Lumpkin and Speer (2003), calculated specifically for the North Atlantic, are indistinguishable from the model overturning. HadCM3 therefore seems to represent a good approximation of our current understanding of the time-mean North Atlantic MOC cell (Gordon et al. 2000). For the Antarctic MOC (Fig. 2b) the estimates of McDonagh and King (2005) and Talley (2003) agree with the model circulation. However, 
those from Ganachaud (2003b) are generally weaker than those from the HadCM3 Antarctic MOC. Salinity and temperature drifts in the Atlantic during the model run mostly relate to a buildup of Antarctic Bottom Water in the Atlantic, suggesting that the model has a slightly too strong Antarctic MOC (Pardaens et al. 2003). Evidence therefore suggests that the mean HadCM3 Antarctic cell is probably stronger than that in reality.

The time-mean $\psi_{N}$ hides considerable interannual and seasonal variability (Fig. 2a). At $26^{\circ} \mathrm{N}$, the mean of $\psi_{N}$ is $16 \mathrm{~Sv}$, the seasonal range is $20 \mathrm{~Sv}$, and the highpass standard deviation $\left(\sigma_{\psi N}\right)$ is $2 \mathrm{~Sv}$. The range in annual-mean $\psi_{N}$ is $4 \mathrm{~Sv}$, and the low-pass standard deviation is $1 \mathrm{~Sv}$. These values seem smaller than the observed decrease in $\psi_{N}$ of $30 \%$ at $26^{\circ} \mathrm{N}$ over $45 \mathrm{yr}$ found by Bryden et al. (2005), though it is worth noting that aliasing seasonal into decadal trends in HadCM3 could give a similar change in magnitude, so the range in $\psi_{N}$ in HadCM3 could be similar to that found in the Bryden et al. (2005) study. The cell center $z_{N}$ (Fig. 2c) has a $\sim 200 \mathrm{~m}$ range of interannual variability, and its average depth is meridionally quite constant, lying between 500 and $750 \mathrm{~m}$. It becomes a little deeper at $30^{\circ} \mathrm{N}$ and there is more variability associated with $z_{N}$ north of $60^{\circ} \mathrm{N}$, where the $\psi_{N}$ is smaller. The Antarctic overturning cell weakens north of $20^{\circ} \mathrm{N}$. At $26^{\circ} \mathrm{N} \psi_{S}$ has a mean of $7 \mathrm{~Sv}$ (Fig. 2b), while the seasonal range can be up to $12 \mathrm{~Sv}$ and the annual variation up to $5 \mathrm{~Sv}$. The cell depth $z_{S}$ (Fig. 2d) changes from 3200 to $4000 \mathrm{~m}$ between $8^{\circ}$ and $16^{\circ} \mathrm{N}$.

It is unclear whether the time-varying HadCM3 circulation matches real ocean variability, because the observational evidence is limited to hydrographic sections repeated only a few times in the last 50 yr (e.g., Koltermann et al. 1999; Bryden et al. 2005). Most studies presume that hydrographic sections depict the mean ocean state, though some evidence (e.g., Thurnherr and Speer 2004) suggests that synoptic hydrographic sections may not be representative of any mean ocean state. But, because there are few repeat data of sufficient quantity, insight is limited on real ocean time variability, and it is difficult to assess whether HadCM3 oceanic variability is a good representation of real ocean variability.

\section{Components of the MOCs}

\section{a. Time-mean results}

The decomposition presented in section 3 allows us to ascribe the North Atlantic and Antarctic MOC over any time scale to vertical shears, and Ekman and external mode components. Over 100 yr, Fig. 3 shows the division of the MOC into these components against latitude for both the North Atlantic and Antarctic cells.

The largest component of $\psi_{N}$ over most latitudes is $\psi_{\rho N}$, or the vertical shears component (Fig. 3a). We calculate this to be between $97 \%$ and $145 \%$ of $\psi_{N}$ for all Southern Hemisphere latitudes, and between $62 \%$ and $101 \%$ between $35^{\circ}$ and $62^{\circ} \mathrm{N}$. Between $5^{\circ}$ and $19^{\circ} \mathrm{N} \psi_{\tau N}$ (the Ekman component) provides the largest contribution (Fig. 3c). Between $19^{\circ}$ and $35^{\circ} \mathrm{N}$, where the Gulf Stream overlies shallow topography and the Deep Western Boundary Current overlies deep topography, the external mode $\left(\psi_{* N}\right)$ component is dominant (Fig. 3e). It ranges between $45 \%$ and a peak of $131 \%$ of $\psi_{N}$ at $28^{\circ} \mathrm{N}$. The shape of $\psi_{* N}$ corresponds closely to the gyre (not shown), and the $28^{\circ} \mathrm{N}$ latitude corresponds to the maximum in North Atlantic gyre transport (with a 100 -yr mean of $50-\mathrm{Sv}$ gyre transport).

In the region of maximum Antarctic MOC strength, $\psi_{\rho S}$ is the largest component of $\psi_{S}$ (Fig. 3b). Where the Antarctic cell is weaker south of $20^{\circ} \mathrm{S}$ and north of $40^{\circ} \mathrm{N}$ (Fig. 2b), the external mode $\psi_{* S}$ is the largest proportion of $\psi_{s}$. The Ekman $\psi_{\tau S}$ component is small everywhere relative to the vertical shears and external mode contributions.

This division into contributions from each component tells us about the information required to assess the mean strength of the MOC in the Atlantic. By selecting latitudes that minimize Ekman or external mode contributions, we can minimize the systematic errors that can arise either from using uncertain bottom pressure (or velocity) data for the calculation of referencelevel velocities or from poorly known wind fields. Thus, Fig. 3 indicates that hydrographic sections, unsupported by bottom pressure (or other reference velocity information) and wind stress information, around $25^{\circ} \mathrm{S}$ or $50^{\circ} \mathrm{N}$ will tend to succeed in time-mean North Atlantic MOC reconstructions because the mean North Atlantic MOC has external mode and Ekman contributions of less than $20 \%$ of the total overturning. In contrast, North Atlantic MOC reconstructions between $8^{\circ}$ and $35^{\circ} \mathrm{N}$ require the time-mean Ekman and external mode contributions to be ascertained. For the Antarctic cell, latitude of $20^{\circ} \mathrm{N}$ confines the non-vertical shears contribution to less than $20 \%$. Thus, for reconstructions based on long-term-averaged hydrography, careful selection of particular zonal sections appears to allow $80 \%$ or greater of the mean MOC of both the North Atlantic and Antarctic cells to be deduced solely by the geostrophic vertical shears component [Eq. (11)].

The error term $\psi_{E N}$ is shown in Fig. $3 \mathrm{~g}$ and $\psi_{E S}$ is in Fig. 3h. The mean error associated with the North Atlantic cell decomposition is $6 \%$ and the maximum is 

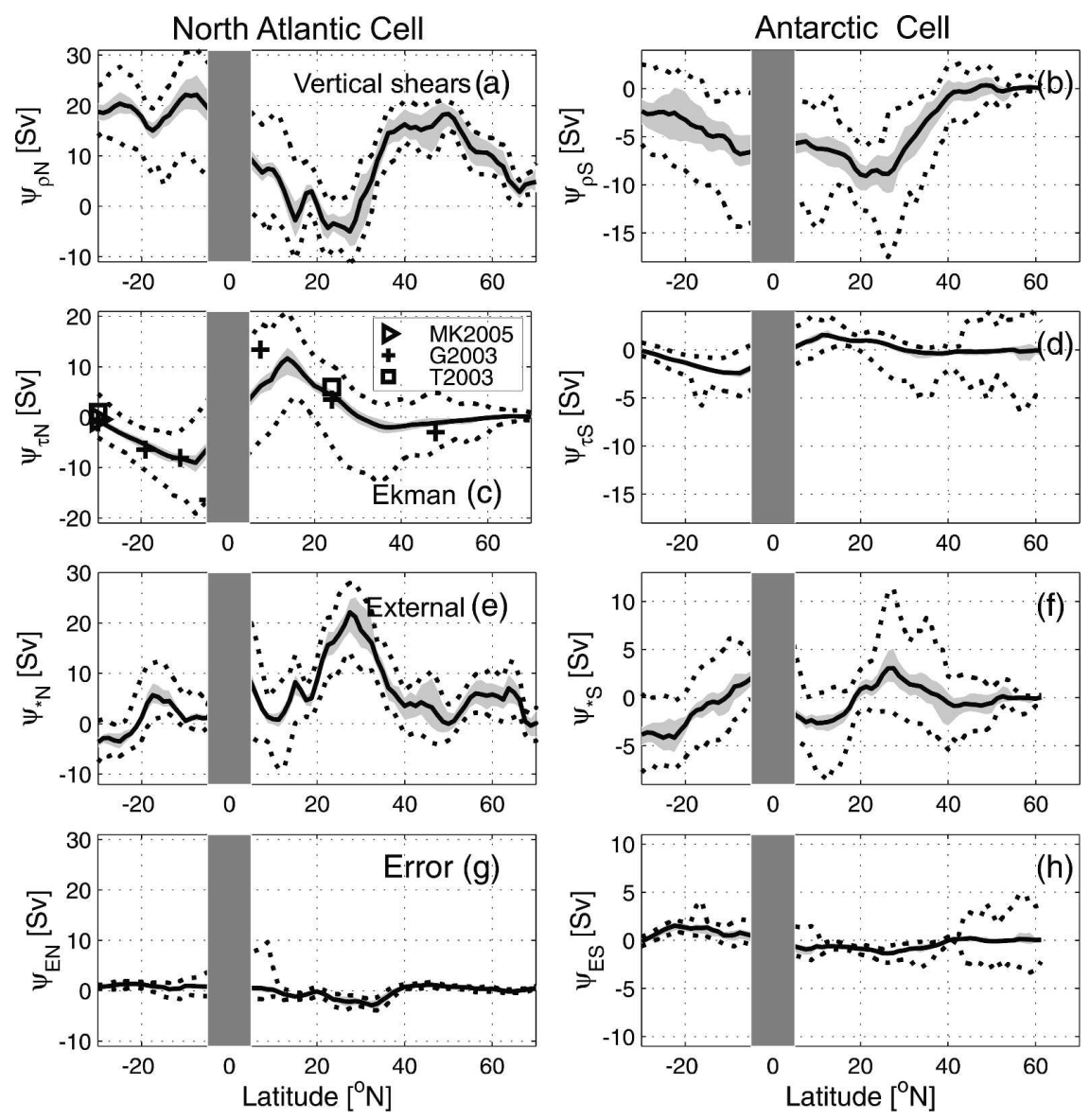

FIG. 3. Components of the Atlantic and Antarctic MOC with inter- and intra-annual variability. The shading shows the interannual variability at each latitude. The dotted lines show the seasonal variation. (a) North Atlantic vertical shears, $\psi_{\rho N}$; (b) Antarctic vertical shears, $\psi_{\rho S}$; (c) North Atlantic Ekman, $\psi_{\tau N}$; (d) Antarctic Ekman, $\psi_{\tau S}$; (e) North Atlantic external mode, $\psi_{* N}$; (f) Antarctic external mode, $\psi_{* S}$; (g) North Atlantic error term, $\psi_{E N}$; and (h) Antarctic error term, $\psi_{E S}$.

$16 \%$ at $32^{\circ} \mathrm{N}$. For the Antarctic cell, the mean of $\psi_{E S}$ is $13 \%$ and the maximum is $35 \%$ at $57^{\circ} \mathrm{N}$, where the Antarctic cell is very weak. This confirms our expectation that $\psi_{E} \neq 0$, but is still small when compared with $\psi_{N}$ and $\psi_{S}$. The error terms represent a combination of both ageostrophic vertical shears and errors in the calculation related to using monthly average model output. As such they are not analyzed here to determine the ageostrophic component, because with the current dataset we cannot separate out these two components of the error term.

Table 1 (first four columns) shows the breakdown of time-mean MOC component at latitudes where hydrographic section has been repeatedly occupied. It confirms that $\psi_{\tau N}$ and $\psi_{* N}$ are small at around $30^{\circ} \mathrm{S}$ and $48^{\circ} \mathrm{N}$. However, we note that the $1.25^{\circ}$ resolution of the model cannot produce a North Atlantic Current (NAC) that is as narrow as that observed (Gordon et al. 2000;
Meinen 2001), and the NAC separates from the coast farther north than in the real ocean. These differences between HadCM3 and the ocean imply that there is not necessarily direct equivalence between model and indi-

TABLE 1. Mean and std dev (e.g., $\sigma_{\psi_{\rho N}}$ is the std dev of the North Atlantic vertical shears $\psi_{\rho N}$ component) of MOC components (Sv) at latitudes commonly used for hydrographic sections.

\begin{tabular}{|c|c|c|c|c|c|c|c|c|c|}
\hline \multirow[b]{2}{*}{ Lat } & \multirow[b]{2}{*}{$\psi_{\rho N}$} & \multirow[b]{2}{*}{$\psi_{\tau N}$} & \multirow[b]{2}{*}{$\psi_{* N}$} & \multicolumn{3}{|c|}{$\begin{array}{l}\text { Low pass } \\
\text { (pentadal) }\end{array}$} & \multicolumn{3}{|c|}{$\begin{array}{l}\text { High pass } \\
\text { (seasonal) }\end{array}$} \\
\hline & & & & $\sigma_{\psi_{\rho N}}$ & $\sigma_{\psi_{\tau N}}$ & $\sigma_{\psi * N}$ & $\sigma_{\psi_{\rho N}}$ & $\sigma_{\psi_{\tau N}}$ & $\sigma_{\psi * N}$ \\
\hline $30^{\circ} \mathrm{S}$ & 18.8 & -0.7 & -3.7 & 0.5 & 0.2 & 0.2 & 0.7 & 0.9 & 0.9 \\
\hline $11^{\circ} \mathrm{S}$ & 21.3 & -8.3 & 1.7 & 0.6 & 0.3 & 0.2 & 2.2 & 1.0 & 0.6 \\
\hline $24^{\circ} \mathrm{N}$ & -3.5 & 4.3 & 16.5 & 0.7 & 0.3 & 0.7 & 0.9 & 1.5 & 1.3 \\
\hline $36^{\circ} \mathrm{N}$ & 13.9 & -1.9 & 7.8 & 1.1 & 0.4 & 0.9 & 0.8 & 1.7 & 0.9 \\
\hline $48^{\circ} \mathrm{N}$ & 17.5 & -1.1 & 1.2 & 1.9 & 0.3 & 2.0 & 0.3 & 1.0 & 0.5 \\
\hline $62^{\circ} \mathrm{N}$ & 8.2 & 0.0 & 5.1 & 1.0 & 0.1 & 0.9 & 0.6 & 0.3 & 0.9 \\
\hline
\end{tabular}



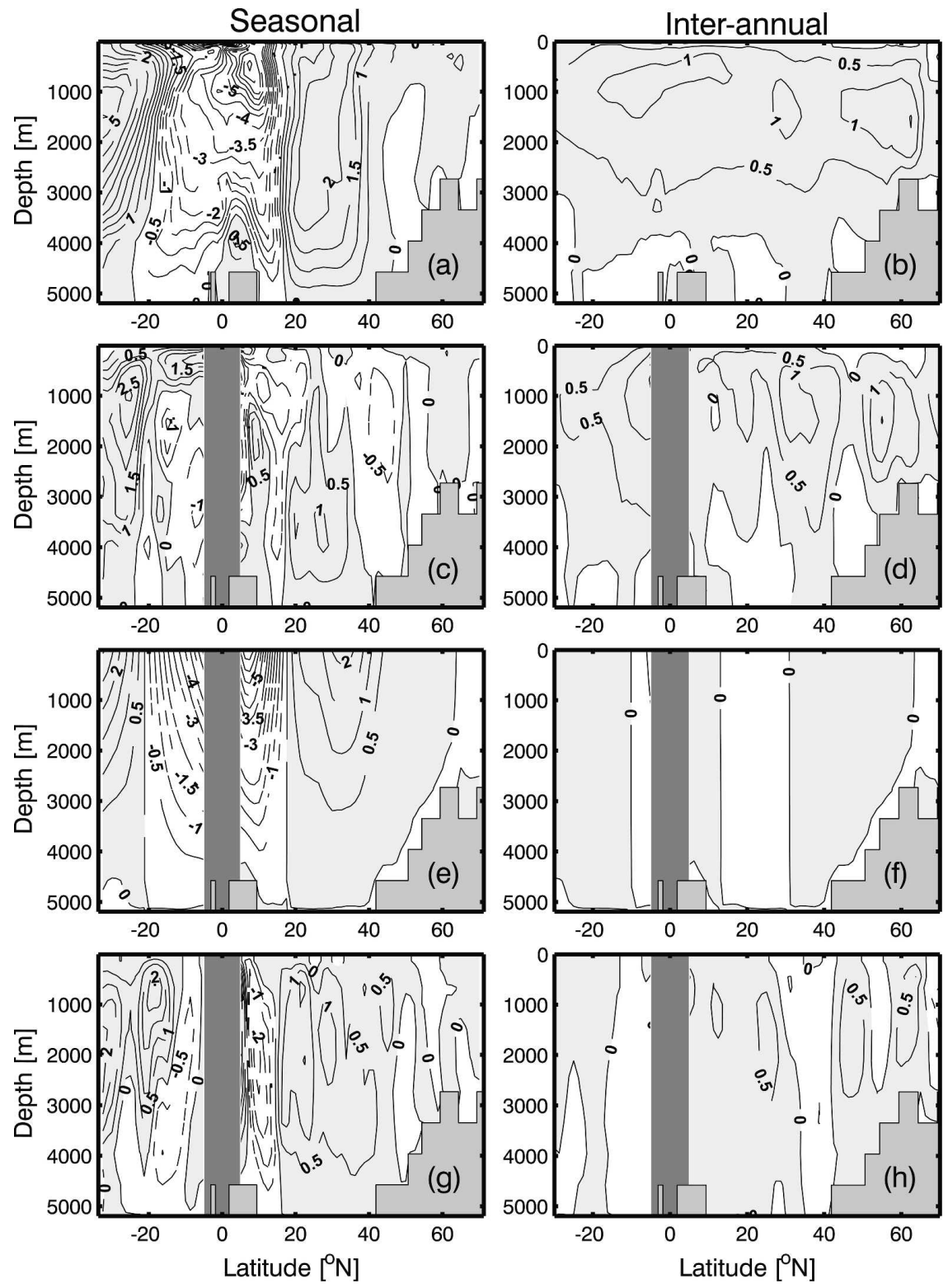

FIG. 4. Mean (a) June-August MOC streamfunction anomaly, and (b) MOC streamfunction anomaly for the $15 \mathrm{yr}$ with highest basin-averaged $\psi_{N}$. Components of (a) are shown in (c) vertical shear $\psi_{\rho}$, (e) Ekman $\psi_{\tau}$, and (g) external mode $\psi_{*}$. The components of (b) are shown in (d) $\psi_{\rho}$, (f) $\psi_{\tau}$, and (h) $\psi_{*}$. Contour interval is $0.5 \mathrm{~Sv}$. Gray shading and positive values indicate clockwise (looking west) overturning; white indicates anticlockwise overturning. The components are not calculated for the equator region from $5^{\circ} \mathrm{S}$ to $5^{\circ} \mathrm{N}$.

vidual hydrographic sections, making the applicability of the results to inverse studies (e.g., Ganachaud 2003b; Lumpkin and Speer 2003) less straightforward. Additionally, we note that these results do not necessarily imply that latitudes with small $\psi_{* N}$ or $\psi_{\tau N}$ are best for MOC monitoring. The MOC is generally monitored for variations through time and, as Table 1 shows, a smaller time-mean component does not necessarily mean a smaller time-variable component.

\section{b. Time-varying components of the MOCs}

Section 5a indicates that a long-term mean of the MOC can be deduced using differing sets of observations at different latitudes. We now address the important question (e.g., Bryden et al. 2005) of temporal variability. Figure 4a shows the mean June-August (JJA) seasonal anomaly of the MOC and Fig. $4 \mathrm{~b}$ shows the mean anomaly in MOC from the $15 \mathrm{yr}$ with highest 

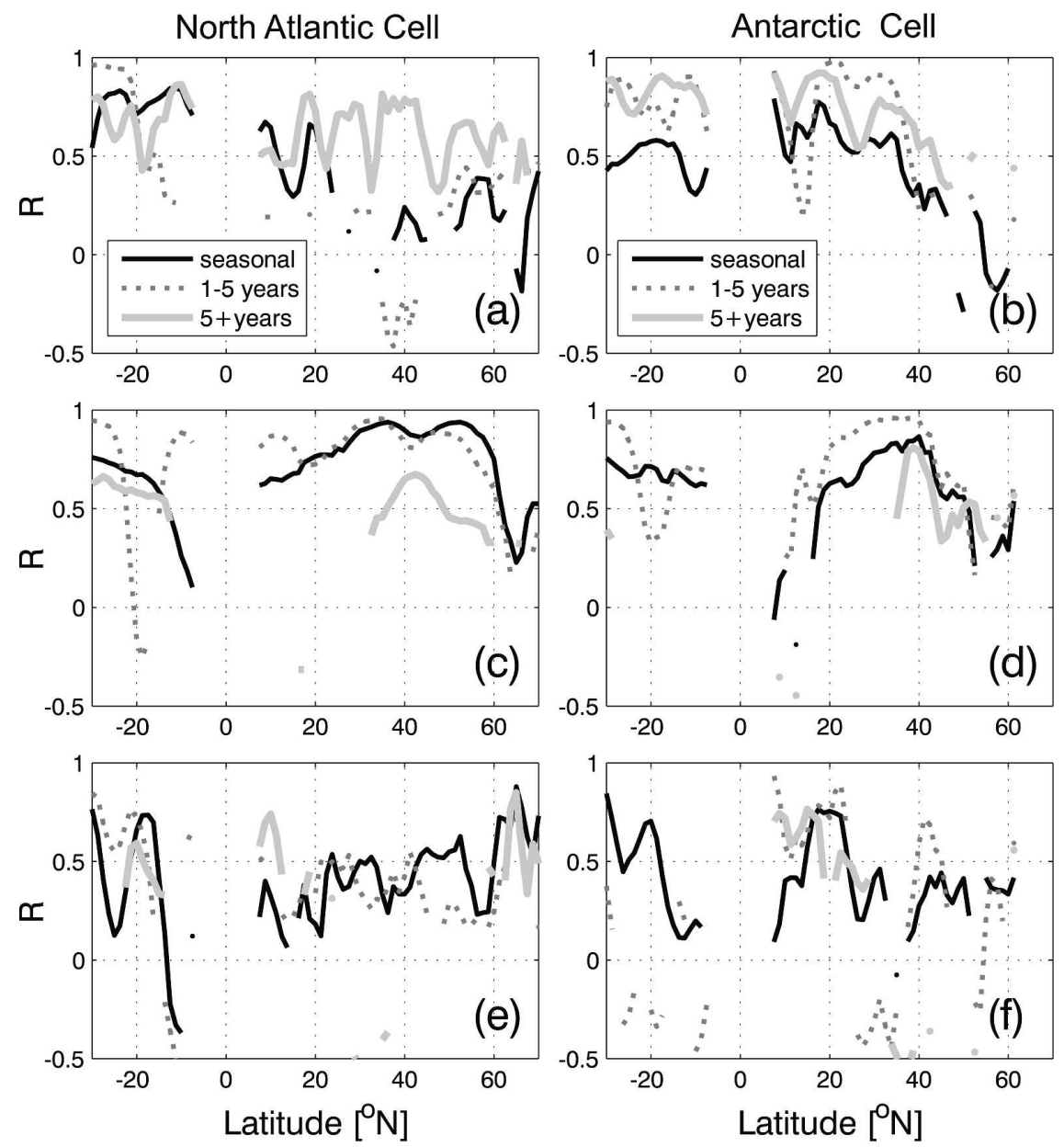

FIG. 5. Correlation coefficients for (a) $\psi_{N}$ and $\psi_{\rho N}$, (b) $\psi_{S}$ and $\psi_{\rho S}$, (c) $\psi_{N}$ and $\psi_{\tau N}$, (d) $\psi_{S}$ and $\psi_{\tau S}$, (e) $\psi_{N}$ and $\psi_{* N}$, and (f) $\psi_{S}$ and $\psi_{* S}$. The components are calculated using monthly data fields and are filtered into seasonal, annual-to-pentadal, and longer-than-pentadal frequencies. Each set of correlations is calculated using $100 \mathrm{yr}$ of control run. Any correlations that have a significance levels lower than $95 \%$ have been removed.

basinwide $\psi_{N}$. The seasonal anomalous MOC largely consists of two counter rotating full-depth cells. In contrast, the annual MOC anomaly is formed of one basinlength full-depth cell. The anomalous MOC structures shown are supported by empirical orthogonal function (EOF) analysis (not shown). Less than $10 \%$ of the anomalous MOC variability is explained by EOFs that exhibit more than one cell in the vertical dimension, indicating that only a small proportion of MOC variability is related to positively correlated North Atlantic and Antarctic anomalous cell overturning. The vast majority of the MOC anomaly relates to full-depth (negatively correlated anomalous $\psi_{N}$ and $\psi_{S}$ ) cells.

Figure 4 shows the decomposition of the anomalous MOC. Figure 5 shows bandpass-filtered correlations between the whole North Atlantic and Antarctic cells and their components. For the North Atlantic cell, Figs.
$4 \mathrm{e}$ and $5 \mathrm{c}$ show that $\psi_{\tau N}$ explains the largest part of the time variability of the MOC in the Northern Hemisphere at seasonal (and generally higher than pentadal) frequencies. For the common North Atlantic monitoring latitudes shown in Table 1 , high-pass-filtered $\sigma_{\psi \tau N}$ is larger than high-pass $\sigma_{\psi_{\rho} N}$ or $\sigma_{\psi_{*} N}$, indicating that the largest time variability is in the Ekman, directly wind driven, component. These $\psi_{\tau N}$ variations tend to explain more than $80 \%$ of the seasonal MOC variation. This supports Dong and Sutton (2001) who found that average zonal wind forcing is the most important boundary condition on overturning at seasonal-to-5-yr time scales south of the overflows. On longer time scales, Figs. $4 \mathrm{~d}$ and $5 \mathrm{a}$ and Table 1 show that $\psi_{\rho N}$ explains the largest proportion of MOC variation. However, in the Southern Hemisphere $\psi_{\rho N}$ is generally the most important component at all time scales; thus, high- 
frequency hydrographic observations are necessary to detect variation in the North Atlantic MOC. The $\psi_{* N}$ component tends to have a larger standard deviation (Table 1) and a greater correlation (Figs. 4g and 5e) with $\psi_{N}$ at shorter time scales, except in the region of the overflows between $62^{\circ}$ and $64^{\circ} \mathrm{N}$ where $\psi_{* N}$ explains most MOC variance at all time scales (Figs. 5a, $5 \mathrm{c}$, and $5 \mathrm{e}$ ).

Monitoring of low-frequency MOC variations (e.g., Koltermann et al. 1999; Bryden et al. 2005) requires different observations at different latitudes, this in spite of the fact that total low-pass MOC is actually almost constant at all latitudes in Table 1 (low-pass $\sigma_{\psi N}$ for all latitudes in Table 1 is $0.6 \mathrm{~Sv} \pm 0.1 \mathrm{~Sv}$, not shown). Low-pass $\psi_{\rho N}$ and $\psi_{* N}$ tend to be negatively correlated in the Northern Hemisphere. This compensation between the components appears to contribute to higher low-pass external mode standard deviation $\sigma_{\psi * N}$ in the Northern Hemisphere relative to the Southern Hemisphere where the components are uncorrelated. Lower low-pass $\sigma_{\psi * N}$ implies that there should be potentially smaller errors in MOC calculation in the Southern Hemisphere resulting from unknown reference-level velocities at these latitudes, because $\psi_{\rho N}$ carries most of the low-pass variability.

The ability to detect low-frequency MOC variability partly depends on the ability to filter high-frequency (seasonal) variability in the components. Generally, it is considered easier to average or high-pass filter the Ekman component, because repeat wind observations are easier to obtain than repeat ocean density observations. Strong seasonality in the hydrographic section observations therefore has the potential to bias MOC estimates. Seasonal MOC variation in $\psi_{\rho N}$ is lowest at $48^{\circ} \mathrm{N}$ (Table 1), suggesting that to minimize seasonality of $\psi_{\rho N}$ this latitude is useful. However, the large contribution of low-frequency $\psi_{* N}$ (Table 1) at this latitude is liable to be a disadvantage. Provided that hydrographic sections can be adequately high-pass filtered, or perhaps observed in a representative season, the results above imply that a southern latitude, perhaps around $25^{\circ} \mathrm{S}$, is potentially a good latitude for monitoring lowfrequency MOC variations, because there is less of a need to obtain bottom pressure or other reference-level velocity information (at least in HadCM3), and seasonal variation in $\psi_{\rho N}$ is smaller than at most other latitudes (Table 1).

For the Antarctic MOC the seasonal anomalies (Figs. $4 \mathrm{a}, 4 \mathrm{e}$, and $5 \mathrm{~d}$ ) are most closely correlated with $\psi_{\tau S}$ at most latitudes, with a stronger correlation with $\psi_{\rho S}$ (Fig. 5 b) only between the equator and $20^{\circ} \mathrm{N}$. The $\psi_{\rho S}$ component becomes the most significantly correlated component at virtually all latitudes at time scales beyond 5 yr. In the interim 1-5-yr band, $\psi_{\tau S}$ and $\psi_{\rho S}$ show very similar levels of correlation with $\psi_{s}$. The Antarctic external mode contribution $\psi_{* S}$ is significant at all frequencies in the subtropics of the Northern Hemisphere. At subannual time scales it is also significant in the Southern Hemisphere.

\section{The relationship between, and causes of, the MOC components}

We have examined the division of the North Atlantic and Antarctic cell strengths into vertical shears, and Ekman and external mode contributions above. It is clear that our vertical shears component is driven solely by baroclinic geostrophic motions, is controlled by local zonal gradients in density (although these gradients may themselves be generated by wind stress), and, in our definition, has no expression in bottom pressure. Similarly, the Ekman component is solely controlled by the zonally averaged zonal wind. The relationships between these components-, and the drivers of the external mode component $\psi_{*}$ are poorly known. Thus, it is worth briefly exploring some interrelationships between the components.

\section{a. Ekman compensation and MOC components}

The question of whether Ekman-driven cells tend to be closed by near-surface baroclinic or barotropic flows has been generally examined indirectly through heat flux considerations by previous authors (e.g., Böning et al. 2001). Over longer time scales these heat flux calculations indicate that Ekman cells must be closed near the surface (e.g., Baehr et al. 2004), indicating that $\psi_{\tau}$ and $\psi_{\rho}$ will be negatively correlated at some lower frequencies. Three models presented by Böning et al. (2001) (geopotential-, isopycnal-, and sigma-type models) support the Gill and Niiler (1973) and Bryan (1982) hypothesis that the density structure does not evolve fast enough to compensate for the seasonal changes in Ekman transport, but can do so at longer time scales. At shorter time scales Bryan (1982) suggests that the seasonal Ekman transport is compensated by nearly depth-independent return flows. This leaves open the possibility that Ekman compensatory flow contributions may arise within the external mode $\psi_{*}$ at these shorter time scales. This question of frequency and latitudinally dependent compensation is also very relevant to the question of the seasonality of vertical shears flow, and is therefore critical to the correct interpretation of transport estimates from one-time (or repeat) hydrographic sections at different latitudes. Thus, the time scale over which Ekman compensation occurs in either $\psi_{\rho}$ or $\psi_{*}$ is worth examining in HadCM3. 

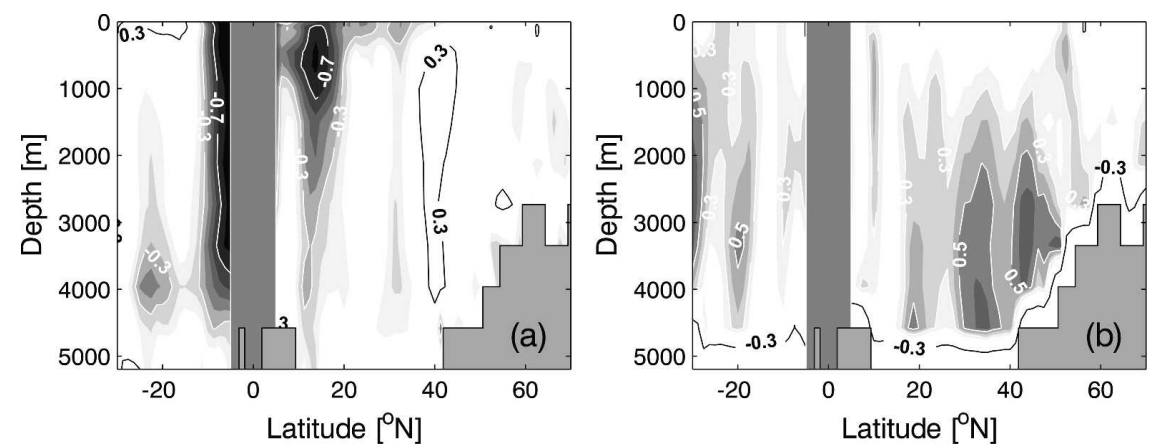

FIG. 6. (a) Contoured correlation coefficient between pentadal (low-pass filtered) $\psi_{\tau}$ and $\psi_{\rho}$. Shaded contours with labeled white contours show regions of negative correlation; the shading interval is 0.1. Black-line (unfilled) contours show regions of positive correlation. For clarity only $-0.7,-0.3,0.3$, and 0.7 are picked out. (b) Contoured correlation between seasonal (high-pass filtered) $\psi_{\tau}$ and $\psi_{*}$. Shaded contours with labeled white contours show regions of positive correlation; the shading interval is 0.1 . Black-line (unfilled) contours show regions of negative correlation. For clarity $-0.3,0.3$, and 0.5 are picked out.

Hydrographic sections are not available at the seasonal time scale to allow for direct observational inferences on basin-wide scales, and subbasin studies such as those by Meinen (2001) or Thurnherr and Speer (2004) are of limited applicability to schemes that require full zonal sections for closure. Figure 6a shows the correlation coefficients between low-pass-filtered (pentadal and lower frequency) $\psi_{\tau}$ and $\psi_{\rho}$. There is a clear strong negative correlation in the tropical regions, particularly in the surface and middepth waters, indicating shallow closure of Ekman-driven surface cells at low frequencies. This correlation drops to insignificant levels for high-pass-filtered time series everywhere, except in the upper (0-2000-m depth) waters within $\approx 8^{\circ}-10^{\circ}$ of the equator, where $R \approx-0.7$ at $z \approx 500 \mathrm{~m}$ (not shown). This result supports the reduction of the importance of baroclinic geostrophic constraints on inversions within the upper parts of tropical hydrographic sections (as suggested by Ganachaud 2003a,b), because single hydrographic sections will be "contaminated" by these rapid baroclinic adjustments. Mid-bandpass-filtered (15 -yr frequencies, not shown) correlation coefficients remain high in this tropical band, and a strong band of shallow $(z \approx 100-500 \mathrm{~m})$ negative correlation $(R=$ -0.5 ) extends north to $40^{\circ} \mathrm{N}$, suggesting strong baroclinic Ekman closure at midlatitudes for interannual Ekman anomalies. Thus, mean annual meridional Ekman transports remain important over a large range of latitudes. Without adequate Ekman information, the uncertainty in baroclinic transports in inverse models would significantly increase. Figure $6 \mathrm{~b}$ shows the correlation coefficients between high-pass-filtered (seasonal) $\psi_{\tau}$ and $\psi_{*}$. Strong correlations $(R>0.7)$ support the Gill and Niiler (1973) and Bryan (1982) hypothesis that the high-frequency Ekman variations are compen- sated by nearly depth-independent return flows, at least outside the Tropics. Additional evidence comes from Figs. $4 \mathrm{a}, 4 \mathrm{e}$, and $4 \mathrm{~g}$, where the shape of the $\psi_{*}$ closely mirrors the seasonal MOC anomaly in $\psi_{\tau}$, suggesting that the anomalous cells tend to be closed by the external mode. At low frequencies there are almost no regions of significant correlations between $\psi_{\tau}$ and $\psi_{*}$ (not shown); however, interestingly, at frequencies between 1 and $5 \mathrm{yr}$ the correlation coefficients between $\psi_{\tau}$ and $\psi_{*}$ rise, generally maintaining the same shape as that shown in Fig. 6b, but with $R$ generally $0.1-0.2$ higher than the high-pass correlation. In HadCM3 the barotropic external mode closure of the Ekman cell appears to be strongest at frequencies between 1 and $5 \mathrm{yr}$.

Wind stress can generate zonal, as well as meridional, Ekman transport, and is a potential driver of density variability within the North Atlantic. However, in HadCM3 we find that the zonal Ekman flow generated by the meridional wind stress is not significantly correlated at any frequency with the vertical shears or the external mode MOC components at any latitude outside of the Tropics (not shown). The small regions of significant correlation in the Tropics reflect the shallow wind-driven tropical cell that is present in this region. The $\psi_{\tau}$ component is positively correlated with the meridional wind stress, but this is simply a reflection of the tendency for meridional and zonal components of wind stress to increase or decrease simultaneously. Thus, it appears that zonal Ekman flow is not a significant contributory component of anomalous Atlantic MOC.

\section{b. The external mode}

The external mode component of meridional overturning is dependent on nonuniform topography in the 


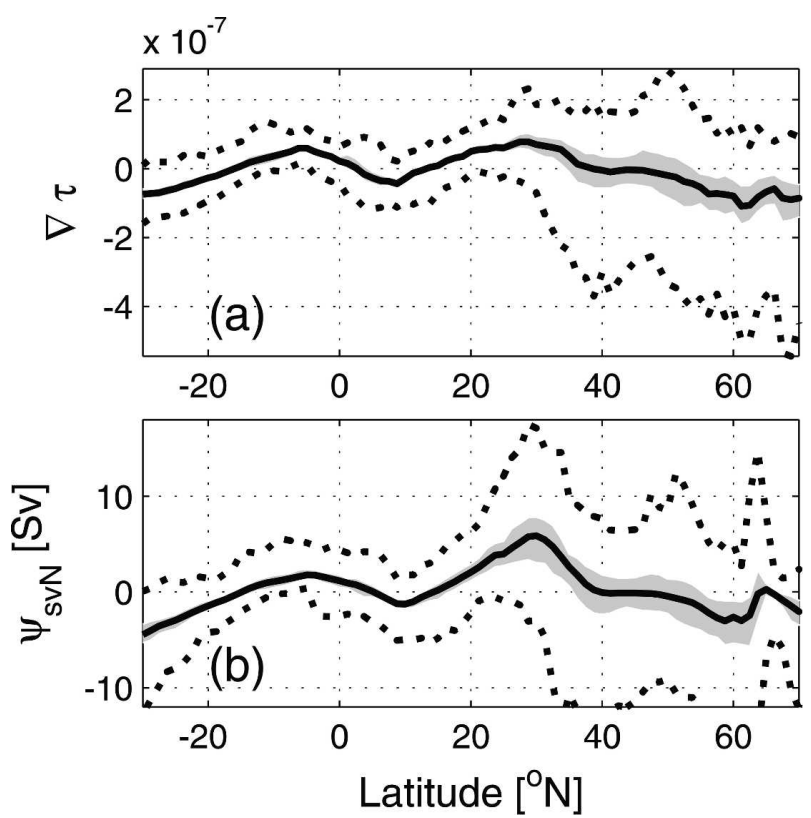

FIG. 7. Mean, interannual limits, and seasonal limits of (a) the zonal mean wind stress curl and (b) the overturning resulting from the component $\psi_{s v N}$. The gray shading indicates the interannual variability at each latitude. The dashed lines show the seasonal variation.

zonal direction and the depth-averaged flow that passes over the topography. Strong flows over variable topography, such as midlatitude gyre circulation, are liable to produce large $\psi_{*}$. For example, on the western boundary region between $20^{\circ}$ and $40^{\circ} \mathrm{N}$ there is a particularly strong $\psi_{* N}$ associated with strong upper water current speeds over shallow topography (not shown).

Various authors (Lee and Marotzke 1998; Koltermann et al. 1999) have suggested that the external mode is, in part, a generalized version of the Sverdrup relation with time dependence and important frictional effects near the western boundary. Figure 7a shows that the region of the strongest $\psi_{* N}$ (Fig. 3e) is associated with the strongest zonally averaged wind stress curl. Theory suggests that response to wind stress curl at midlatitudes should be primarily barotropic, and should be rapidly transmitted to the western boundary by barotropic Rossby waves (Böning et al. 2001), ensuring that the Sverdrup balance is valid over time periods of a few months. This implies that seasonal variation in the external mode should be observable in the Sverdrup balance if it represents $\psi_{* N}$, though weaker stratification and shallower topography at high latitudes will tend to erode the relationship north of the subtropical gyre (Webb and Suginohara 2001).

When we use the Sverdrup balance to calculate an overturning by closing the transport with western boundary flow between 0 and $1000 \mathrm{~m}$, we obtain the strong time-dependent Sverdrup overturning $\psi_{s v N}$ shown in Fig. 7b. Although this calculation contradicts the steady-state flat-bottomed Sverdrup assumptions, it clarifies the role played by the wind stress curl in the overturning, and demonstrates that Sverdrup transport, with non-curl-driven closure, explains the meridional shape of $\psi_{* N}$ to first order. We note that our closure assumptions may not be well justified at some latitudes, which may partially explain why $\psi_{s v N}$ is much weaker than $\psi_{* N}$. At many latitudes a deeper southwardflowing western boundary current, which is not in response to a Sverdrup interior, is omitted from $\psi_{s v N}$ by the simplifying closure assumption that only permits non-Sverdrup balance transport in the upper waters. Bryden and Imawaki (2001) also find that the Sverdrup transport is much weaker than the observed transport. Thus, Fig. 7b only approximates Fig. 3e using the top1000-m closure assumption, although it resembles the shape (though again not magnitude) of the HadCM3 gyre transport much more closely (not shown). Alternative calculations confining non-Sverdrup balance transport to the westernmost oceanic HadCM3 grid cell or grid cells (which produce a meridionally varying closure depth) produce results that bear no resemblance to the external mode, and experiments using shallower or deeper meridionally constant closures give results with less semblance to the external mode than those in Fig. $7 b$ (not shown). These results suggest that no simple alternative closure gives a significantly better representation of the non-Sverdrup western boundary flows.

The correlations between time-varying $\psi_{* N}$ and $\psi_{s v N}$ explain less than $10 \%$ of the total variance over most of the regions where wind stress curl effects are large (Fig. 8a). The Sverdrup balance explains a larger proportion of the time variability in the regions of the tropical and subtropical gyres, with the correlation diminishing toward the poles. In the Northern Hemisphere, $\psi_{s v N}$ explains up to a maximum of $80 \%$ of the variance in the 1-5-yr-frequency band at $10^{\circ} \mathrm{N}$. Over most of the rest of the North Atlantic $\psi_{s v N}$ does not explain more than $\approx 30 \%$ of the variability, and for the whole Atlantic the mean explained variability in all frequency bands is $11 \%$. Because the Sverdrup balance is tending to leave $70 \%-90 \%$ of the external mode variability unexplained, it is probably not adequate to use the Sverdrup balance to determine the decadal change in the external mode (the approach taken by Koltermann et al. 1999).

\section{c. The relationship between the external mode and the vertical shears components}

Because bottom pressure gradients are the result of column-integrated density, we expect a relationship be- 

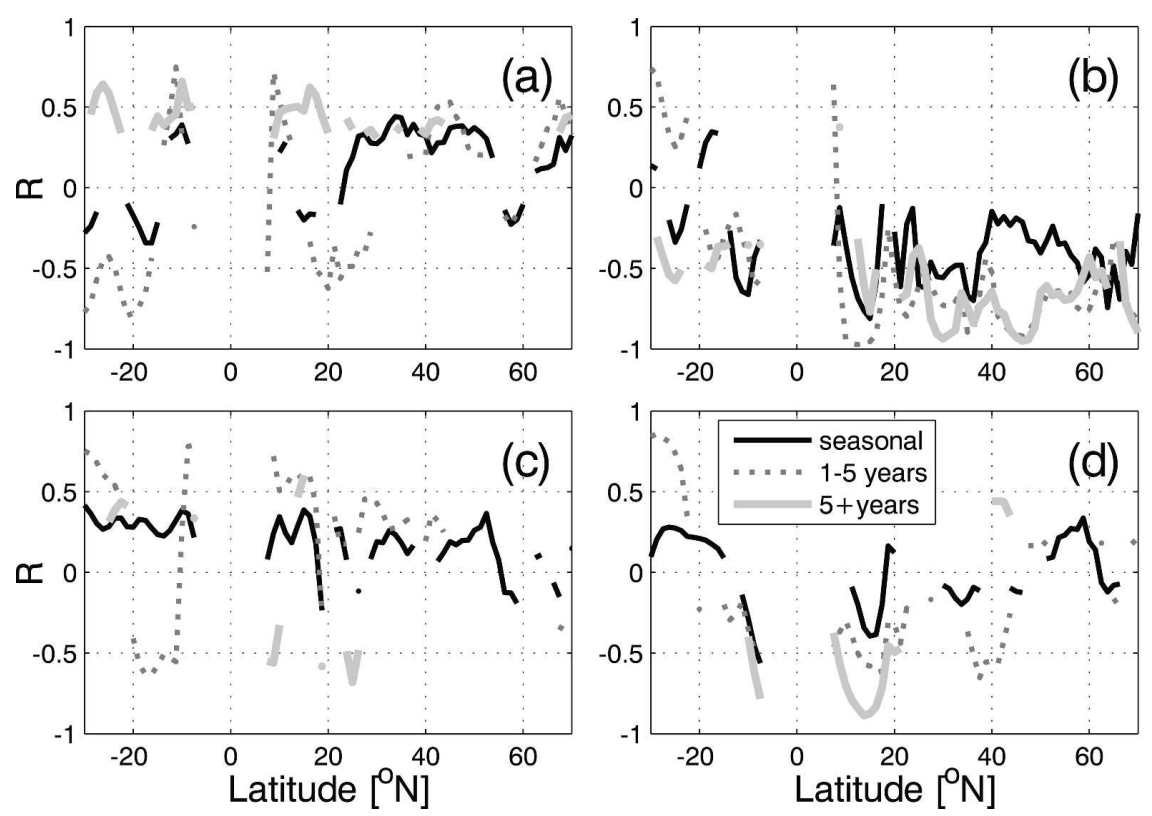

FIG. 8. Correlation coefficients for (a) $\psi_{* N}$ and $\psi_{s v N}$, (b) $\psi_{* N}$ and $\psi_{\rho N}$, (c) $\psi_{* N}$ and $\psi_{\tau N}$, and (d) $\psi_{\rho N}$ and $\psi_{\tau N}$. The components are calculated using monthly data fields. They are filtered into seasonal, annual-to-pentadal, and longer-than-pentadal frequencies. Each set of correlations is calculated using $100 \mathrm{yr}$ of control run. Any correlations that have a significance level lower than $95 \%$ have been removed.

tween $\psi_{* N}$ and $\psi_{\rho N}$. Figure $8 \mathrm{~b}$ shows that in the North Atlantic the majority of $\psi_{* N}$ variance is explained by $\psi_{\rho N}$, indicating a significant relationship between the components because they are both dependent on zonal gradients in density. This can be seen by considering the approximate form of the depth-averaged vorticity equation,

$$
\begin{aligned}
\beta \boldsymbol{v}_{*} \simeq & \frac{\partial}{\partial y}\left(\frac{g}{\rho_{0} h_{b}} \int_{-h_{b}}^{0} \int_{z}^{0} \frac{\partial \rho}{\partial x} d Z d z\right) \\
& -\frac{\partial}{\partial x}\left(\frac{g}{\rho_{0} h_{b}} \int_{-h_{b}}^{0} \int_{z}^{0} \frac{\partial \rho}{\partial y} d Z d z\right)-\frac{\partial}{\partial y}\left(\frac{\tau_{x}}{\rho_{0} h_{b}}\right) \\
& +\frac{\partial}{\partial x}\left(\frac{\tau_{y}}{\rho_{0} h_{b}}\right) .
\end{aligned}
$$

The depth-independent horizontal flow largely depends upon the joint effect of the baroclinity, relief term, and wind stress curl. This provides a link between $\psi_{* N}, \psi_{\rho N}$, and $\psi_{\tau N}$.

Figures $8 \mathrm{a}$ and $8 \mathrm{~b}$ imply that while $\psi_{* N}$ in a timemean sense may primarily be forced by wind stress curl, it is gradients in density, imposed on top of bottom topography, that are important in determining the external mode component $\psi_{*}$. This is supported by Fig. 9, which demonstrates a very strong negative correlation between low-pass-filtered $\psi_{*}$ and $\psi_{\rho}$. There are signifi- cant negative correlations in the regions north of $20^{\circ} \mathrm{N}$, where the NAC is confined to the western boundary of the Atlantic. Midbandpass correlations show a very similar pattern, though the correlations are a little stronger than the low-pass correlations in the tropical regions between $15^{\circ} \mathrm{S}$ and $15^{\circ} \mathrm{N}$. High-pass-filtered time

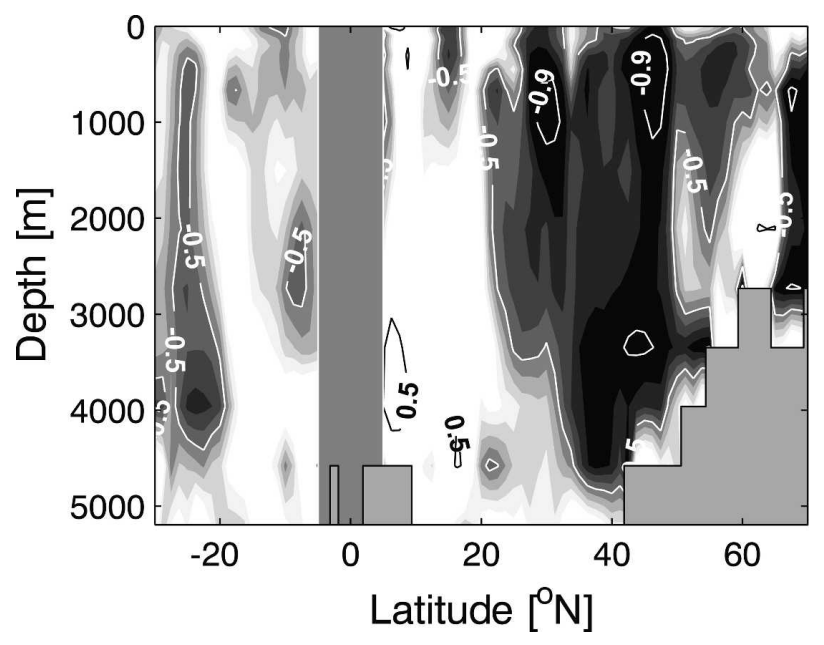

FIG. 9. The correlation between pentadal and lower-frequency (low-pass filtered) $\psi_{*}$ and $\psi_{\rho}$. Shaded contours with labeled white contours show regions of negative correlation; the shading interval is 0.1. Black-line (unfilled) contours show regions of positive correlation. For clarity only $-0.9,-0.5,0.5$, and 0.9 are picked out. 
series show much weaker, mostly insignificant, correlation, except again in the tropical regions. This result disagrees with Meinen (2001) who found a weak positive correlation of $R=0.29$ between baroclinic and barotropic northward flow (totaling $\approx 95 \mathrm{~Sv}$ ) in the region at about $42^{\circ} \mathrm{N}$. However, given that Meinen's results are from an open-ended short section and do not relate directly to $\mathrm{MOC}$, it is difficult to interpret the possible discrepancy between his results and the current study.

The gradients in density that support $\psi_{\rho}$ will also be dependent on the zonal expression of meridional differences in surface buoyancy forcing. Detailed investigation of the nature of the relationship between $\psi_{\rho}, \psi_{*}$, and meridional differences in surface buoyancy forcing is outside the scope of this paper [see Haines and Old (2005) for a study of thermal surface forcing and thermal North Atlantic oceanic variability in HadCM3].

This correlation between $\psi_{* N}$ and $\psi_{\rho N}$ does highlight a difficulty in whether we should use a barotropic or nonuniform flow to close the $\boldsymbol{v}_{\rho}$ velocity term, and this decision changes the balance of velocities between the $\boldsymbol{v}_{\rho}$ and $\boldsymbol{v}_{*}$ terms. Using zero bottom velocities, that is, a uniform barotropic assumption to close $\boldsymbol{v}_{\rho}$, where $\boldsymbol{v}_{\rho}$ is calculated using cross-basin gradients, generates a different balance to the MOC decomposition. This alternative method means we would obtain a difference in the component velocity fields between the equator and $28^{\circ} \mathrm{N}$. When examined in terms of $\psi_{N}$, a large proportion (up to $15 \mathrm{~Sv}$ ) of the MOC passes from $\psi_{* N}$ to $\psi_{\rho N}$ (not shown). The Antarctic cell distribution of MOC also changes significantly. Almost all Northern Hemisphere $\psi_{S}$ (up to $9 \mathrm{~Sv}$ ) switches from $\psi_{\rho S}$ to $\psi_{* S}$ while in the Southern Hemisphere, most of the $\psi_{S}$ MOC switches from $\psi_{* S}$ to $\psi_{\rho S}$. Thus, the choice of a barotropic or a nonuniform closure for $\psi_{*}$ and $\psi_{\rho}$ makes a significant difference to the shape of the MOC decomposition. Interestingly, in favor of our presented (nonuniform) decomposition, the correlations between $\psi_{N}$ and $\psi_{\rho N}$ are generally (slightly) higher and the correlations between $\psi_{S}$ and $\psi_{\rho S}$ are much higher than in the case of the uniform barotropic closure with zero bottom velocities. Moreover, the meridionally averaged correlation between $\psi_{\rho}$ and $\psi_{*}$ for both cells remains approximately equal for either method (not shown). This highlights that it is not possible, using either barotropic or nonuniform flow to close the $\boldsymbol{v}_{\rho}$ velocity term, to entirely divide geostrophic flow into that obtained from density gradients and that from bottom pressure gradients, because both are dependent on density gradients [see Eq. (14)]. This does not detract from our assertion that the decomposition (as outlined in section 3) quantifies the proportions of MOC dependent on hydrogra- phy, bottom pressure (or suitably averaged LADCP), and wind stress, respectively. We suggest that for two reasons the decomposition we present is slightly preferable to one using a barotropic $\boldsymbol{v}_{\rho}$ closure. First, the correlations between $\psi$ and $\psi_{\rho}$ are slightly higher, and because the density field tends to be the best-known part of any hydrographic section, it is preferable to know in detail the component of $\psi$ that explains the largest part of the time variability (without being dependent on knowledge of bottom pressure or other reference velocities); second, this velocity decomposition is also directly comparable with previous decompositions (Hall and Bryden 1982; Lee and Marotzke 1998).

\section{Summary and conclusions}

We have provided the explicit observational requirements of the decomposition outlined by Lee and Marotzke (1998) and Baehr et al. (2004) and an examination of the interdependent nature of each of the components. The application of the decomposition to the Atlantic Ocean of HadCM3 quantifies the components at all latitudes and frequencies, and therefore the accuracy of the detection of the time-mean (e.g., Lumpkin and Speer 2003) and time-variable (e.g., Bryden et al. 2005; Koltermann et al. 1999) MOC cells.

The division into contributions from each component indicates the information that is required to assess the mean strength of the MOC cells in the Atlantic. By selecting latitudes that minimize Ekman or external mode contributions, we minimize the systematic errors that will arise from using uncertain bottom pressure (or reference-level velocity) data, or errors from poorly known wind fields. HadCM3 indicates that hydrographic sections, unsupported by bottom pressure information and wind stress information, at $\approx 25^{\circ} \mathrm{S}$ are good for deducing both time-mean and time-varying MOC. This is because first, the mean North Atlantic MOC has external mode and Ekman contributions of less than $20 \%$ of the total overturning; and second, the proportion of the MOC variability resulting from the external mode (and direct wind forcing) is also lower in the Southern Hemisphere. This implies that there should be potentially smaller errors in MOC calculation because of unknown reference-level velocities at these latitudes. This is despite the fact that total non-Ekman MOC high-frequency variation is actually higher in the Southern Hemisphere. Low-frequency variation of the external mode is relatively small in the Southern Hemisphere. Provided that low-frequency (nonseasonal) $\psi_{\rho N}$ can either be adequately represented by hydrographic observations, which itself is not a trivial issue (Thurnherr and Speer 2004), or observed in a representative 
season, a southern latitude around $25^{\circ} \mathrm{S}$ is potentially a good latitude for monitoring low-frequency MOC variations, because it minimizes the need for bottom pressure or other reference-level velocity information. We note that this study does not include an examination of the effect of including information from instrument arrays such as the Florida Strait cable (e.g., Baringer and Larsen 2001), which will alter the balance of available information at some latitudes (Baehr et al. 2004).

For the Antarctic cell, a latitude of $20^{\circ} \mathrm{N}$ confines the nonvertical shears contribution to less than $20 \%$. Thus, for reconstructions based on long-term-averaged hydrography, careful selection of particular zonal sections appears to allow $80 \%$ or greater of the mean MOC of both the North Atlantic and Antarctic cells to be deduced solely from hydrographic sections, with no additional information requirements.

The external mode component $\left(\psi_{*}\right)$ has been shown to be extremely important where Western Boundary Currents impinge on topography, and also in the area of the overflows. This term allows us to obtain a quantitative assessment of the effect of bottom pressure information at these locations on different time scales. At worst case, omission can result in time-mean MOC errors in excess of $100 \%$ for the North Atlantic in the $25^{\circ}-32^{\circ} \mathrm{N}$ belt and at $62^{\circ} \mathrm{N}$. These estimates quantify the importance of bottom pressure and other arrays at these latitudes (e.g., Lee et al. 1996; Bacon 1998; Baringer and Larsen 2001). The Antarctic cell external mode is particularly important around $22^{\circ} \mathrm{S}$, where it contributes $70 \%$ of the time-mean Antarctic MOC, and $75 \%$ at $\sim 48^{\circ} \mathrm{N}$. We note that where reference levels are used (e.g., Bacon 1998; Koltermann et al. 1999) to minimize the impact of the external mode, error estimates associated with the omission of $\psi_{*}$ will not be directly comparable with the values of $\psi_{*}$ obtained in this study.

We have shown that the mean seasonal and mean interannual anomalous MOC tends consist of full-depth cells, with two cells for the seasonal MOC and just one cell spanning the whole North Atlantic for the mean interannual anomaly. These anomalous cells explain $90 \%$ of the time variability of HadCM3 North Atlantic MOC. As Dong and Sutton (2001, 2002a) suggest, the Ekman transport explains the largest part of the time variability of the MOC in the Northern Hemisphere on seasonal-to-5-yr time scales. Over longer time scales the vertical shears component $\psi_{\rho N}$ explains most variability. However, $\psi_{\rho N}$ is the most important component at all time scales in the Southern Hemisphere, where variation in the Ekman transport is less important.

We find that wind-generated Ekman transport cells are closed near the surface in tropical regions at all frequencies. This has implications for the representativeness of hydrographic sections in tropical regions as suggested by Ganachaud (2003a) and arguably observed by Thurnherr and Speer (2004). Midlatitude baroclinic closure becomes larger at time scales between 1 and 5 yr. At higher (seasonal) frequencies, outside the Tropics, the depth-independent external mode tends to close the Ekman cell. Zonal Ekman flows do not correlate (at zero lag) with the vertical shears or external mode component at any latitude or frequency. (Except possibly for the shallow tropical cell, which we cannot investigate here because the decomposition breaks down where beta effects begin to dominate within $\approx 5^{\circ}$ of the equator.)

Sverdrup balance explains the shape of the external mode MOC component to first order, however it is much weaker than the model external mode, or gyre, backing up Bryden and Imawaki (2001). "Second order" deviations in the shape of $\psi_{* N}$ and $\psi_{s v N}$ are dependent on fluctuations in $\psi_{\rho N}$. Correlations between time-varying external mode and the Sverdrup balance explain less than $10 \%$ of the variance over regions where wind stress curl effects are large. The Sverdrup balance does tend to explain a higher proportion of the time variability at lower frequencies, but even here it does not explain more than $30 \%$ of the external mode variability. Thus, it is probably not adequate to use the Sverdrup balance to determine the external mode changes for detecting decadal change in the MOC (as tried by Koltermann et al. 1999). So, while it is important to include the effects of changes in the external mode for detecting interannual or decadal change in the MOC, this cannot be done with the Sverdrup balance alone.

For most of the Northern Hemisphere there is a very strong negative correlation between the vertical shears and the external mode contribution. This is related to the confinement of currents to the western boundary shelf region. When boundary currents move off the shelf they change from contributing to the external mode to the vertical shears component. We note that if an alternative closure is used, where the external mode is calculated from bottom velocities (giving a uniform barotropic closure to the vertical shears component), then there is no change in this strong interdependence of $\psi_{*}$ and $\psi_{\rho}$. Therefore, perhaps the components should be seen as providing more of an observational, rather than a dynamic, decomposition.

Previous authors (Hirschi et al. 2003; Baehr et al. 2004; Vellinga and Wood 2004) have looked at the specific instrumental setup, using predeployed (e.g., Baringer and Larsen 2001) and new (Hirschi et al. 2003; Baehr et al. 2004) instrumentation, that could be used 
to detect change in the Atlantic MOC. We have demonstrated here, in more general terms, the observational requirements for the deduction of MOC strengths from one-time or repeat hydrographics sections, without addressing these same instrumental issues. Future work will use inversions to investigate how including additional assumptions and information affects the deduction of decadal changes in MOC, heat, and freshwater transport.

Acknowledgments. We thank the Natural Environmental Research Council for funding this work through the Coupled Ocean-Atmosphere Processes and European Climate (COAPEC) Programme, Grant NER/T/ S/2000/00303.

\section{REFERENCES}

Bacon, S., 1998: Decadal variability in the outflow from the Nordic seas to the Deep Atlantic Ocean. Nature, 394, 871-874.

Baehr, J., J. Hirschi, J. O. Beismann, and J. Marotzke, 2004: Monitoring the meridional overturning circulation in the North Atlantic: A model-based array design study. J. Mar. Res., 62, 283-312.

Baringer, M. O., and J. C. Larsen, 2001: Sixteen years of Florida Current transport at $27^{\circ} \mathrm{N}$. Geophys. Res. Lett., 28, 31793182.

Böning, C. W., C. Dieterich, B. Barnier, and Y. L. Jia, 2001: Seasonal cycle of meridional heat transport in the subtropical North Atlantic: A model intercomparison in relation to observations near $25^{\circ}$ N. Progress in Oceanography, Vol. 48, Pergamon, 231-253.

Bryan, K., 1962: Measurements of meridional heat transport by ocean currents. J. Geophys. Res., 67, 3403-3414.

_ 1982: Seasonal variation in meridional overturning and poleward heat transport in the Atlantic and Pacific Oceans: A model study. J. Mar. Res., 40, 39-53.

Bryden, H. L., and S. Imawaki, 2001: Ocean heat transport. Ocean Circulation and Climate: Observing and Modelling the Global Ocean, G. Siedler, J. Church, and J. Gould, Eds., Academic Press, 455-474.

- H. R. Longworth, and S. A. Cunningham, 2005: Slowing of the Atlantic meridional overturning circulation at 25 degrees N. Nature, 438, 655-657.

Collins, M., S. F. B. Tett, and C. Cooper, 2001: The internal climate variability of HadCM3, a version of the Hadley Centre coupled model without flux adjustments. Climate Dyn., 17, 61-81.

Cooper, C., and C. Gordon, 2002: North Atlantic oceanic decadal variability in the Hadley Centre coupled model. J. Climate, 15, 45-72.

Cox, M. D., 1984: A primitive equation 3-dimensional model of the ocean. GFDL Ocean Group Tech. Rep. 1, 143 pp.

Dickson, R. R., and J. Brown, 1994: The production of North Atlantic deep water: Sources, rates, and pathways. J. Geophys. Res., 99 (C6), 12 319-12 341.

Dong, B. W., and R. T. Sutton, 2001: The dominant mechanisms of variability in Atlantic Ocean heat transport in a coupled ocean-atmosphere GCM. Geophys. Res. Lett., 28, 2445-2448.

_- and —_, 2002a: Adjustment of the coupled ocean- atmosphere system to a sudden change in the Thermohaline Circulation. Geophys. Res. Lett., 29, 1728, doi:10.1029/ 2002GL015229.

— , and - 2002b: Variability in North Atlantic heat content and heat transport in a coupled ocean-atmosphere GCM. Climate Dyn., 19, 485-497.

Ganachaud, A. S., 2003a: Error budget of inverse box models: The North Atlantic. J. Atmos. Oceanic Technol., 20, 16411655.

, 2003b: Large-scale mass transports, water mass formation, and diffusivities estimated from World Ocean Circulation Experiment (WOCE) hydrographic data. J. Geophys. Res., 108, 3213, doi:10.1029/2002JC001565.

Gill, A. E., and P. P. Niiler, 1973: The theory of the seasonal variability in the ocean. Deep-Sea Res., 20, 141-178.

Gordon, C., C. Cooper, C. A. Senior, H. Banks, J. M. Gregory, T. C. Johns, J. F. B. Mitchell, and R. A. Wood, 2000: The simulation of SST, sea ice extents and ocean heat transports in a version of the Hadley Centre coupled model without flux adjustments. Climate Dyn., 16 (2-3), 147-168.

Haines, K., and C. Old, 2005: Diagnosing natural variability of North Atlantic water masses in HadCM3. J. Climate, 18, 1925-1941.

Hall, M. M., and H. L. Bryden, 1982: Direct estimates and mechanisms of ocean heat transport. Deep-Sea Res., 29, 339-359.

Hirschi, J., J. Baehr, J. Marotzke, J. Stark, S. Cunningham, and J. O. Beismann, 2003: A monitoring design for the Atlantic meridional overturning circulation. Geophys. Res. Lett., 30, 1413, doi:10.1029/2002GL016776.

Koltermann, K. P., A. V. Sokov, V. Tereschenkov, S. A. Dobroliubov, K. Loracher, and A. Sy, 1999: Decadal changes in the thermohaline circulation of the North Atlantic. Deep-Sea Res. II, 46 (1-2), 109-138.

Lee, T., and J. Marotzke, 1998: Seasonal cycles of meridional overturning and heat transport of the Indian Ocean. J. Phys. Oceanogr., 28, 923-943.

Lee, T. N., W. E. Jones, R. J. Zantopp, and E. R. Fillenbaum, 1996: Moored observations of western boundary current variability and thermohaline circulation at $26.5^{\circ} \mathrm{N}$ in the subtropical North Atlantic. J. Phys. Oceanogr., 26, 962-983.

Lumpkin, R., and K. Speer, 2003: Large-scale vertical and horizontal circulation in the North Atlantic Ocean. J. Phys. Oceanogr., 33, 1902-1920.

McDonagh, E. L., and B. A. King, 2005: Oceanic fluxes in the South Atlantic. J. Phys. Oceanogr., 35, 109-122.

Meinen, C. S., 2001: Structure of the North Atlantic current in stream-coordinates and the circulation in the Newfoundland basin. Deep-Sea Res., 48, 1553-1580.

Pardaens, A. K., H. T. Banks, J. M. Gregory, and P. R. Rowntree, 2003: Freshwater transports in HadCM3. Climate Dyn., 21, 177-195.

Pope, V. D., M. L. Gallani, P. R. Rowntree, and R. A. Stratton, 2000: The impact of new physical parametrizations in the Hadley Centre climate model: HadAM3. Climate Dyn., 16 (2-3), 123-146.

Roberts, M. J., and R. A. Wood, 1997: Topographic sensitivity studies with a Bryan-Cox-type ocean model. J. Phys. Oceanogr., 27, 823-836.

Saunders, P. M., and B. A. King, 1995: Oceanic fluxes on the WOCE A11 section. J. Phys. Oceanogr., 25, 1942-1958.

Talley, L. D., 2003: Shallow, intermediate, and deep overturning component of the global heat budget. J. Phys. Oceanogr., 33, $530-560$. 
Thorpe, R. B., J. M. Gregory, T. C. Johns, R. A. Wood, and J. F. B. Mitchell, 2001: Mechanisms determining Atlantic thermohaline circulation response to greenhouse gas forcing in a non-flux-adjusted coupled climate model. J. Climate, 14, 3102-3116.

— , R. A. Wood, and J. F. B. Mitchell, 2004: Sensitivity of the modelled thermohaline circulation to the parameterisation of mixing across the Greenland-Scotland ridge. Ocean Modell., 7 (3-4), 259-268.

Thurnherr, A. M., and K. G. Speer, 2004: Representativeness of meridional hydrographic sections in the western South Atlantic. J. Mar. Res., 62, 37-65.

Vellinga, M., and R. A. Wood, 2002: Global climate impacts of a collapse of Atlantic thermohaline circulation. Climate Change, 54 (3), 251-267.

- and - 2004: Timely detection of anthropogenic change in the Atlantic meridional overturning circulation. Geophys. Res. Lett., 31, L14203, doi:10.1029/2004GL020306.

Webb, D. J., and N. Suginohara, 2001: The interior circulation of the ocean. Ocean Circulation and Climate: Observing and Modelling the Global Ocean, G. Siedler, J. Church, and J. Gould, Eds., Academic Press, 205-214.

Willebrand, J., and Coauthors, 2001: Circulation characteristics in three eddy-permitting models of the North Atlantic. Progress in Oceanography, Vol. 48, Pergamon, 123-161.

Wunsch, C., 1996: The Ocean Circulation Inverse Problem. Cambridge University Press, $442 \mathrm{pp}$. 